\title{
Cloning of the mouse sodium iodide symporter and its expression in the mammary gland and other tissues
}

\author{
B Perron, A-M Rodriguez, G Leblanc and T Pourcher \\ Laboratoire de Physiologie des Membranes Cellulaires, Université de Nice Sophia-Antipolis, Commissariat à l'Energie Atomique-LRC16V, \\ Centre National de la Recherche Scientifique-UMR6078, F-06238 Villefranche-sur-Mer, France \\ (Requests for offprints should be addressed to T Pourcher, Laboratoire Jean Maetz, BP68, F-06238, Villefranche-sur-Mer, France; Email: pourcher@obs-vlfr.fr)
}

\begin{abstract}
Iodide concentration in milk by mammals is a necessary step for thyroid hormone synthesis by the newborn. With the purpose of using the mouse as an animal model to analyse the role of the sodium iodide symporter (NIS) in iodide transport and its regulation in the mammary gland, mouse NIS (mNIS) cDNA was isolated from lactating mice. The cloned sequence shows an open reading frame of 1854 nucleotides encoding a protein of 618 amino acids highly homologous to the rat and human NIS (95\% and $81 \%$ identity respectively). Expression of mNIS in
\end{abstract}

cultured mammalian cells induced cellular iodide accumulation. This iodide uptake process is sodium dependent and inhibited by thiocyanate and perchlorate. Tissue distribution analysis revealed that mNIS mRNAs are predominantly expressed in thyroid, stomach and in the lactating mammary gland and are present to a lower extent in several other tissues. Our data show for the first time that the level of mNIS mRNA is upregulated in the mammary gland during lactation.

Journal of Endocrinology (2001) 170, 185-196

\section{Introduction}

Current understanding of the mechanism involved in iodide transfer across epithelia mostly relies on studies in the thyroid tissue or derived cell lines. It has been established in thyrocytes that iodide uptake is mediated by the sodium iodide symporter (NIS) localised in the basolateral membrane (reviewed in De La Vieja et al. 2000, Spitzweg et al. 2000). Molecular identification of the symporter was achieved by cloning of rat NIS (rNIS) from the thyroid cell line FRTL-5 (Dai et al. 1996). This breakthrough led to subsequent identification of the human NIS (hNIS) sequence (Smanik et al. 1996) and related exon-intron organisation (Smanik et al. 1997). These findings had considerable impact on the understanding of the physiology, hormonal regulation (essentially thyroid-stimulating hormone) and pathophysiology of the thyroid (recently reviewed in De La Vieja et al. 2000, Spitzweg et al. 2000).

The molecular identification of NIS from the thyroid allowed the characterisation of the molecular mechanism involved in iodide transport across extrathyroidal tissues and more specifically in the mammary gland (recently reviewed in De La Vieja et al. 2000). Transport and concentration of iodide into the milk by the lactating mammary gland has been known for decades (BrownGrant 1961, Grosvenor 1963). The milk iodide is used by the newborn for synthesis of thyroid hormone, a hormone which plays an essential role in development of the nervous system and bones (Williams et al. 1998, Chan \& Kilby 2000). Expression of NIS mRNA has been detected by RT-PCR in the mammary gland of lactating Wistar rats (Ajjan et al. 1998b) and in the human breast (Smanik et al. 1997, Spitzweg et al. 1998). Furthermore, NIS was immunodetected in mammary lobular cells in the human (Vayre et al. 1999) and in the basolateral membrane of the mammary alveolar cells in lactating rats (Cho et al. 2000, Tazebay et al. 2000).

There is also evidence that NIS expression and/or activity is triggered in mammary tumours (Thorpe \& Briand 1984, Kilbane et al. 2000, Tazebay et al. 2000). On this basis, it has been suggested that NIS expression and activity could be used for diagnosis and treatment of breast cancer (Tazebay et al. 2000, Welcsh \& Mankoff 2000).

Several recent studies provide evidence that iodide transport in the rodent and human mammary glands is regulated by several different hormones, including prolactin, oxytocin, oestrogens and retinoic acid (Cho et al. 2000, Kogai et al. 2000, Rillema et al. 2000, Tazebay et al. 2000) but to date, no clear overall picture of the contribution of individual and/or combined hormones has emerged.

Many studies on iodide accumulation in the mammary gland were made on mice (Thorpe \& Briand 1984, Rillema \& Yu 1996, Rillema et al. 2000, Tazebay et al. 2000). Furthermore, analysis of mammary gland development and function (lactogenesis and lactation processes) were mostly carried out with mice. These studies showed 
that a complex balance of several hormones (oestrogens, progesterone, prolactin) and paracrine mechanisms control this organ (Tucker 1994). Recent gene targeting technology has resulted, in particular, in knockout mice for oestrogen (Bocchinfuso \& Korach 1997), progesterone (Shyamala 1999) and prolactin (Bole-Feysot et al. 1998) receptors which are helping to define hormonal control of mammary gland development and function.

In spite of recent progress, understanding of the iodide transport regulation in the mouse mammary gland is limited by the lack of molecular information on the NIS in this animal. To fill this gap, we cloned the mouse NIS (mNIS) from the lactating mammary gland. We showed that expression of this protein in cultured mammalian cells induces sodium iodide symport activity. mNIS mRNA distribution was analysed in mammary glands at different developmental stages and in several other tissues. We found that the highest levels of NIS mRNA were detected in the thyroid, stomach and lactating mammary gland.

\section{Materials and Methods}

\section{Materials}

All buffer reagents were purchased from Sigma-Aldrich Chemical Co. (St Quentin, France). Restriction endonucleases and T4 DNA Ligase were from New England Biolabs (Beverly, MA, USA). A TA cloning kit was purchased from Promega (Madison, WI, USA). Escherichia coli XL2-Blue cells were from Stratagene (La Jolla, CA, USA). Oligonucleotide primers were synthesised by Sigma-Genosys Ltd (Cambs, UK). Primers were designed using the primer selection program from the Virtual Genome Center (http://alces.med.umn.edu/rawprimer. html). Standard nucleotide-nucleotide BLAST searches were carried out using a program provided by the National Center for Biotechnology Information (http://www. ncbi.nlm.nih.gov/).

\section{RT-PCR cloning of mNIS cDNA from the mouse mammary gland}

Animals were supplied by the Animal Centre, University of Nice Sophia Antipolis, France. All animal care and experiments were performed in accordance with the Institutional Guidelines of Animal Experimentation. Lactating mice (crossing of male DBA2 and female C57BL6) were killed by cervical dislocation. The caudal and inguinal pairs of mammary glands were removed, quickly frozen and stored in liquid nitrogen. Frozen tissues were powdered and poly(A) mRNAs were isolated using the Poly(A) Pure mRNA Isolation Kit from Ambion Inc. (Austin, TX, USA). First-strand cDNAs were synthesised using SuperScript reverse transcriptase (Life Technologies, Cergy Pontoise, France). PCR reactions were performed by means of a Robocycler (Stratagene) using the Expand high fidelity PCR system (Roche Diagnostics, Meylan, France). Hot Start PCR reactions were carried out using Hot Start tubes (Molecular Bio-products Inc., San Diego, CA, USA) according to the manufacturer's instructions. PCR (and rapid amplification of cDNA ends (RACE)) reactions were carried out as follows. The overall procedure includes a pre-soak, at $94{ }^{\circ} \mathrm{C}$ for $3 \mathrm{~min}, 35-40$ cycles of denaturation at $94{ }^{\circ} \mathrm{C}$ for $50 \mathrm{~s}$, an annealing step at $50{ }^{\circ} \mathrm{C}$ for $50 \mathrm{~s}$, an extension at $69^{\circ} \mathrm{C}$ for $1-3 \mathrm{~min}$, and finally an extension at $69^{\circ} \mathrm{C}$ for $6-8 \mathrm{~min}$. PCR fragments were gel purified and cloned into the pGEM-T plasmid (Promega).

A cDNA fragment $(450 \mathrm{bp})$ corresponding to the $3^{\prime}$ extremity of the open reading frame (ORF) and part of the non-coding region was amplified using two primers (5'-GTGGTGCTCTCATCAGCTACCTAACT- ${ }^{\prime}$ and 5'-TTCCTTGGTGGATAGACAACCAAC-3') derived from two overlapping mouse expressed sequence tags (ESTs) (AA615690 and AA690196). Additional cDNA fragments of the mNIS ORF were amplified using a specific sense primers derived from rNIS and specific antisense primer derived from the already identified mNIS sequence. Two steps were carried out using the following primers: 5'-CAGCCTCGCTCAGAACCATTCCCGG ATCAAC-3' (nucleotides 769-799 of rNIS: sense strand) and 5'-CGAGGCCTGTGATTGGCTTTC-3' (nucleotides 1934-1953 of mNIS: antisense strand); $5^{\prime}{ }^{-}$ GCAGTGCCGACGACTTCTTTAC-3' (nucleotides 234-255 of rNIS: sense strand) and 5'-CTACAAATGT CCAGAAGGTGTAGCG-3' (nucleotides 784-808 of mNIS: antisense strand). Missing $5^{\prime}$ and $3^{\prime}$ ends of mNIS cDNA were obtained by RACE using the Marathon cDNA Amplification Kit (Clontech Lab. Inc., Paolo Alto, CA, USA). The primers used for the $5^{\prime}$ RACE experiment were 5'-CTGGTAGGTGCTGGTAAGGCC-3' (nucleotides 400-420: antisense strand) and 5'CACAGAAACTTGAGACCGTAGCG-3' (nucleotides 307-329: antisense strand). Primers 5'-ATTACTGTGG TGGGACCTCGC-3' (nucleotides 1731-1751: sense strand) and 5'-CTCTCTGAATGGTTGGACCGTC-3' (nucleotides 1968-1989: antisense strand) were used for the 3' RACE experiment. All identified fragments were cloned into the pGEM-T plasmid and sequenced.

Three PCR products carrying complementary and partially overlapping stretches (F1-F3) of the mNIS sequence were used to construct a cDNA carrying the complete ORF. The first product (F1) harboured the first 750 bases of the mNIS ORF preceded by a sequence containing a new NotI restriction site and a Kozak sequence just upstream of the initiation codon of the ORF. This fragment was amplified using the following primers: 5'-AAGCGGCCGCCACCATGGAGGGCGCGGAGG CAGG-3' (nucleotides 62-84: sense strand) and 5'-CTA CAAATGTCCAGAAGGTGTAGCG-3' (nucleotides 784-809: antisense strand). The second fragment F2 
carrying the central part of the NIS ORF (950 bp), was synthesised using primers 5'-GCGCTCATCCTGAAC CAAGTGACCGGG-3' (nucleotides 520-546: sense strand) and 5'-CTCTCCAGGCGGGTACAGTGT-3' (nucleotides 1453-1473: antisense strand). The third fragment (F3, $870 \mathrm{bp}$ ) harbouring the $5^{\prime}$ extremity of the ORF, was synthesised using primers $5^{\prime}$-CTCTTC CTGGCCTGTGCCTAC-3' (nucleotides 1087-1107: sense strand) and 5'-CGAGGCCTGTGATTGGCT TTC-3' (nucleotides 1934-1953: antisense strand). For each amplification condition, cDNA fragments from two independent PCR reactions were ligated into pGEM-T. Recombinant pGEM-Ts (pGEM-T-F1, pGEM-T-F2 and pGEM-T-F3) with an inverse orientation for the sense strand of mNIS with regard to the sense strand of the $\beta$-galactosidase gene were selected. The obtained cDNA fragments were sequenced in both directions (sequencing service, Genome Express SA, Grenoble, France). The complete mNIS ORF was engineered by joining the three complementary DNA fragments in pGEM-T recombinant plasmids: AatII-XhoI fragment from pGEM-T-F1 (AatII in position 20 in pGEM-T and Xhol in position 684 in mNIS); Xhol-BlpI fragment from pGEM-T-F2 (Xhol in position 684 and BlpI in position 1420 in mNIS); and BlpI-SpeI DNA fragment from pGEM-T-F3 (BlpI in position 1420 in $\mathrm{mNIS}$ and SpeI in position 55 in pGEM-T). The resulting plasmid was called pGEM-T-mNIS.

\section{PCR amplification of $m$ NIS genomic DNA fragments}

Kidneys were dissected from two male (DBA2 line) and two female (C57BL6 line) mice. Genomic DNA was prepared using the DNAeasy Tissue Kit (Qiagen S.A., Courtaboeuf, France). Four independent PCR reactions were carried out as described in the RT-PCR cloning section using the following primers: 5'-GTGGTGC TCTCATCAGCTACCTAACT-3' (nucleotides 16731698: sense strand) and 5'-CGAGGCCTGTGATTG GCTTTC-3' (nucleotides 1934-1954: antisense strand). The sequences of the extremities of the obtained PCR fragments (three clones for each PCR reaction) were obtained.

\section{RT-PCR amplification of $m$ NIS $c D N A$ from mouse thyroid}

Thyroids were dissected from male mice (DBA2) (to avoid any possible contamination with mammary gland mRNAs). Total RNAs were prepared using an RNeasy Kit (Qiagen). RT-PCR reactions were carried out as described above. Three different cDNA fragments corresponding to F1, F2 and F3 described above that contain together the full mNIS ORF were amplified. The sequence of each PCR fragment was determined by automatic sequencing.
Functional expression of $m$ NIS in COS-7 cells

mNIS cDNA from pGEMT-mNIS was subcloned into the eukaryotic expression vector pcDNA3-1 (Invitrogen, Groningen, The Netherlands) using the two flanking NotI restriction sites. Recombinant pcDNA3-1 carrying the mNIS cDNA in either direction were selected by enzyme digestion and purified (EndoFree Plasmid Maxi Kit; Qiagen). COS-7 cells (ECACC no. 87021302) were transfected with either the recombinant or empty vectors using Lipofectamine Plus Reagent (Life Technologies). Iodide uptake experiments were conducted at $37^{\circ} \mathrm{C}$ unless stated otherwise, as described by Weiss et al. (1984).

\section{RT-PCR analysis of mNIS expression}

Analysis of mNIS expression in different developmental stages of the mammary gland and 16 others tissues was carried out using the Mouse Rapid-Scan Gene Expression Panel (Origene, Rockville, MD, USA). In general, experiments were performed according to the manufacturer's recommendations except that the taq polymerase (Roche) was used at a concentration four times higher than suggested. Two independent experiments were carried out with different sets of primers: primer set 1 (see above); primer set 2 including 5'-CTCTTCCTGGCC TGTGCCTAC-3' (nucleotides 1087-1107: sense strand); and 5'-CGAGGCCTGTGATTGGCTTTC-3' (nucleotides 1934-1954: antisense strand). The protocol included a pre-soak step at $94^{\circ} \mathrm{C}$ for $3 \mathrm{~min}, 36$ cycles in the experiment using primer set 1 and 35 cycles using primer set 2 of denaturation at $94^{\circ} \mathrm{C}$ for $30 \mathrm{~s}$, an annealing step at $60{ }^{\circ} \mathrm{C}$ for $1 \mathrm{~min}$, and an extension at $72^{\circ} \mathrm{C}$ for $2 \mathrm{~min}$, and a final extension step at $72{ }^{\circ} \mathrm{C}$ for $5 \mathrm{~min}$. PCR products were separated on agarose gels (1\%) and stained with $1 \times$ GelStar stain (FMC BioProduct, Rockland, ME, USA). Gel images were captured with a DC120 Kodak Digital Camera (Eastman Kodak Company, Rochester, NY, USA) and the bands were analysed using Kodak Digital Science 1D Analysis Software. Band intensities were assessed applying the Gaussian model, from the sum of the background-subtracted pixel values of each band. For each series (i.e. PCR experiments with the same primers and cDNA dilution), the results were normalised using the lactating mammary gland as reference (set at 100\%). An average of the results with each cDNA was determined and the standard error was calculated.

Another set of radioactive semi-quantitative RT-PCR was also carried out. RNAs were extracted (RNeasy Kit; Qiagen) from dissected thyroid, lactating mammary gland, stomach and liver. Once first-strand DNAs were prepared (using Superscript reverse transcriptase), PCR reactions were performed using taq polymerase (Roche) following the manufacturer's recommendations except that the dNTP concentration was halved and $\left[\alpha_{-}{ }^{33} \mathrm{P}\right] \mathrm{dATP}$ was added ( $5 \mathrm{mCi}$ per reaction of a $2 \cdot 5 \mathrm{Ci} / \mathrm{mol}$ solution) by 
means of an i-cycler apparatus (Bio-Rad S.A., Ivry sur Seine, France). The protocol included a pre-soak step at $94{ }^{\circ} \mathrm{C}$ for $3 \mathrm{~min}, 15-27$ cycles of denaturation at $94{ }^{\circ} \mathrm{C}$ for $30 \mathrm{~s}$, an annealing step at $60{ }^{\circ} \mathrm{C}$ for $1 \mathrm{~min}$, and an extension at $72{ }^{\circ} \mathrm{C}$ for $2 \mathrm{~min}$, and a final extension step at $72{ }^{\circ} \mathrm{C}$ for $5 \mathrm{~min}$. Primer set $1,5^{\prime}$-GCAGTGCCGAC GACTTCTTTAC-3' (nucleotides 188-209: sense strand) with 5'-GGGCTTGGTTCACACCATACAT-3' (nucleotides 835-856: antisense strand), was used for NIS gene amplification. $\beta$-Actin primers $\left(5^{\prime}\right.$-AACACCCCA GCCATGTACGTAG-3' and $5^{\prime}$-GTGTTGGCATAGA GGTCTTTACGG-3') were used in a parallel reaction to enable a semi-quantitative analysis. To minimise errors caused by possible differences in the concentrations of the template cDNAs of the PCR experiments carried out with NIS primers versus control primers, a PCR master mix was prepared without primers, split into two tubes and then primers (NIS or $\beta$-actin specific) were added. Different numbers of PCR cycles (three per experiment) were used, ranging from 25 to 27 for NIS and from 15 to 17 for $\beta$-actin. PCR products were separated on $4 \%$ acrylamide/ bisacrylamide gels in $1 \times \mathrm{TBE}$. Gels were fixed (4\% acetic acid), dried and then exposed to X-ray film. Autoradiographs were scanned and analysed using Kodak Digital Science 1D Analysis Software. The linearity of each amplification reaction set was graphically assessed and the NIS: $\beta$-actin ratio was calculated from deduced values.

\section{Results}

Identification of a cDNA from mouse mammary gland highly homologous to $r$ NIS

Examination of the EST sequences listed in the WasUHHMI Mouse EST project (Washington University, School of Medicine, St Louis, MO, USA) revealed two overlapping mouse cDNA sequences (EST accession numbers AA690196 and AA615690) highly homologous to rNIS. The first sequence (AA690196) was isolated from mouse mammary gland (C57BL/6J mouse strain), and has a length of $431 \mathrm{bp}$. It shares a high homology to the last 20 nucleotides of rNIS ORF and to part of its $3^{\prime}$-untranslated region. The second sequence (AA615690), isolated from the mouse myoblast cell line $\mathrm{C} 2 \mathrm{C} 12$, is $436 \mathrm{bp}$ in length and matches the $237 \mathrm{bp}$ extremity of rNIS ORF and a small part of the 3 '-untranslated region. RT-PCR experiments carried out in the presence of primers derived from these two EST sequences and with total mRNA extracted from lactating mouse mammary gland led to amplification of a $450 \mathrm{bp}$ fragment. Using this $450 \mathrm{bp}$ fragment as a starting sequence, most of the ORF of the cDNA was amplified in a stepwise fashion using specific antisense primers corresponding to the mouse sequence identified in the previous round of amplification, and sense primers derived from upstream regions of the rNIS sequence. The $5^{\prime}$ and $3^{\prime}$ extremities of this sequence were identified using RACE.
The isolated cDNA is $2280 \mathrm{bp}$ in length with a predicted ORF of 1854 nucleotides (Fig. 1). This cDNA shows $88 \%$ identity with rNIS cDNA, larger differences being observed in untranslated regions. The $5^{\prime}$ untranslated region is $64 \mathrm{bp}$ long, i.e. $40 \mathrm{bp}$ shorter than in the rNIS cDNA sequence. The identified 3 '-untranslated region is $362 \mathrm{bp}$ in length and therefore 500 nucleotides shorter than the rNIS cDNA sequence. Since Northern blot analysis indicates that the full-length mouse mRNA is $2800 \mathrm{bp}$ in length (data not shown), part of the non-coding $3^{\prime}$ extremity remains to be identified. Comparison of several amplified cDNA sequences showed a polymorphism at position 1905 where $\mathrm{T}$ and $\mathrm{C}$ were found. The corresponding codons encode for a Val residue (GTT) and an Ala residue (GCT) in position 614 of the NIS protein. Since mRNAs were prepared from lactating females that were obtained by crossing males of line DBA 2 and females C57BL6, the genotypes of the parental mouse lines were analysed. Female C57BL6 are heterozygous ( $\mathrm{T}$ and $\mathrm{C}$ ) in this position whereas male DBA2 are homozygous $(\mathrm{T})$. This observation should be taken into consideration when polyclonal antibodies against the C-terminus extremity of rNIS are used with mouse C57BL6 (see Caturegli et al. 2000); part of the protein may not be detected by all antibodies directed against rNIS.

The ORF encodes a protein of 618 amino acids sharing $95.5 \%$ identity (98\% similarity) with the rNIS sequence (Fig. 2). The homology of the protein with hNIS is also very high, being $89 \cdot 5 \%$ identical ( $81 \%$ similarity). The following observations further highlight the strength of the homology between mNIS, rNIS and hNIS primary amino acid sequences. Three charged residues (Asp16, Glu79 and Arg208), with a potential catalytic importance, that are localised in putative transmembrane spanning helices I, II and of VI in the revised topological model of rNIS (Levy et al. 1998), are conserved at equivalent positions in the mouse protein. In addition, the three $\mathrm{N}$-linked glycosylation sites (Asn225, 485 and 497), the potential cAMP phosphorylation site (549-KRSS-552) and the two protein kinase C (PKC) phosphorylation sites at position 548TKR-550 and 593-TKK-595 found in the mNIS protein were also localised at equivalent position in the rNIS protein. Finally, four residues of hNIS or rNIS (Gly93, Gln267, Thr354 and Gly538), in positions corresponding to identified point mutations which result in thyroid iodide transport defects and congenital hypothyroidism in the human (Pohlenz \& Refetoff 1999, Fujiwara et al. 2000), are also conserved in the mouse protein. These data indicate that the isolated sequence is the mNIS orthologue of rNIS and hNIS.

\section{Functional expression of mNIS in mammalian cells}

The cloned mammary gland ORF was inserted into the mammalian expression vector pcDNA3.1. In order to optimise expression, the non-coding regions of the mNIS 


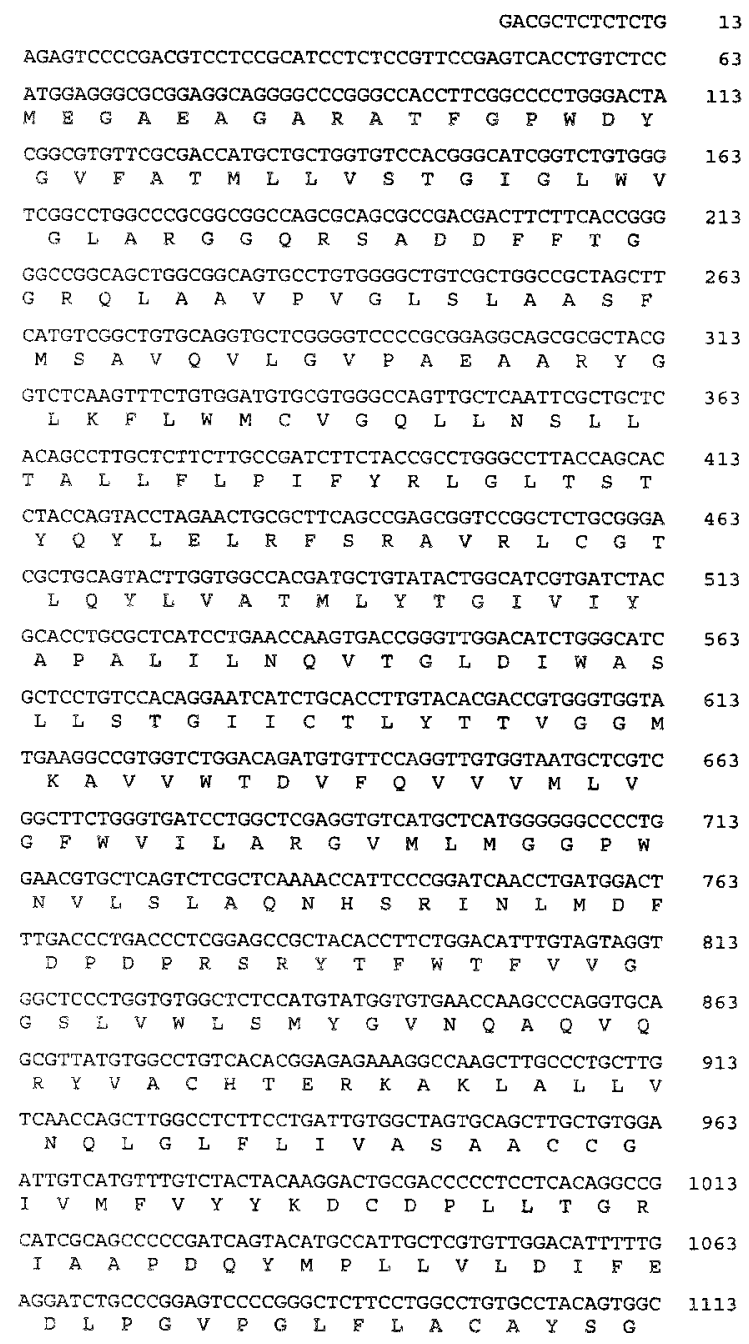

ACCCTCAGCACCGCGTCCACCAGTATCAACGCTATGGCAGCTGTAAC'TGT 1163

$\begin{array}{llllllllllllllllll}351 & T & L & S & T & A & S & T & S & I & N & A & M & A & A & V & T & V\end{array}$

GGAAGACCTCATCAAGCCCAGGATGCCTAGCCTGGCACCCCGGAAGCTGG 1213

$\begin{array}{llllllllllllllllll}368 & \mathbf{E} & \mathrm{D} & \mathrm{I} & \mathrm{I} & \mathrm{K} & \mathrm{P} & \mathrm{R} & \mathrm{M} & \mathrm{P} & \mathrm{S} & \mathrm{L} & \mathrm{A} & \mathrm{P} & \mathrm{R} & \mathrm{K} & \mathrm{I} & \mathrm{V}\end{array}$

TTTTCATCTCTAAAGGGCTCTCATTCATCTATGGCTCAACCTGCCTCACT 1263

385

$\begin{array}{llllllllllllllllll}F & I & S & K & G & L & S & F & I & Y & G & S & T & C & L & T\end{array}$

GTGGCTGCTCTGTCCTCGCTGCTGGGAGGTGGGGTCCTCCAGGGCTCTTT 1313

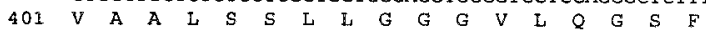

CACCGTGATGGGTGTCATCAGTGGGCCTCTCCTTGGCGCTTTCACCCTCG 1363

$\begin{array}{llllllllllllllllll}418 & T & V & M & G & V & I & S & G & P & L & L & G & A & F & T & L & G\end{array}$

GGATGCTGCTCCCAGCCTGCAACACGCCAGGCGTCCTCTCCGGGCTGACA 1413

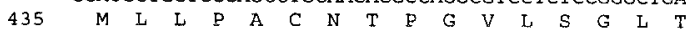

GCAGGCTTAGCTGTATCCCTGTGGGTGGCCGTGGGGGCCACACTGTACCC 1463

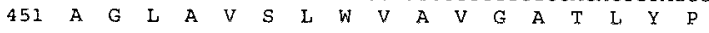

GCCTGGAGAGCAGACCATGGGGGTGCTGCCCACCTCGGCTGCGGGATGCA 1513

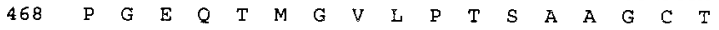

CCAATGCCTCGGTCCTCCCGAGCCCACCCGGAGCTGCCAACACTTCCAGA 1563

$\begin{array}{lllllllllllllllllllllll}485 & N & A & S & V & L & P & S & P & P & G & A & A & N & T & S & R\end{array}$

GGGATCCCCAGTTCTGGAATGGACTCGGGCCGCCCAGCCTTTGCCGACAC 1613

$\begin{array}{llllllllllllllllll}501 & G & I & P & S & S & G & M & D & S & G & R & P & A & F & A & D & T\end{array}$

CTTTTATGCTGTCTCATATCTCTACTACGGGGCTCTGGGCACTTTGACCA 1663

$\begin{array}{lllllllllllllllllllll}518 & F & Y & A & V & S & Y & L & Y & Y & G & A & L & G & T & \text { I } & T & T\end{array}$

CTATGCTTTGTGGTGCTCTCATCAGCTACCTAACTGGCCCCACCAAGCGC 1713

$\begin{array}{lllllllllllllllll}535 & M & \text { L } & C & G & A & L & I & S & Y & L & T & G & P & T & K & R\end{array}$

AGCTCCCTGGGCCCTGGATTACTGTGGTGGGACCTCGCTCGGCAGACAGC 1763

$\begin{array}{llllllllllllllllll}551 & S & S & L & G & P & G & L & L & W & W & D & L & A & R & Q & T & A\end{array}$

ATCTGTGGCCCCAAAGGAGGACACCACCACCCTGGAGGACAGCCTGGTTA 1813

$\begin{array}{llllllllllllllllll}568 & S & V & A & P & K & E & D & T & T & T & L & E & D & S & L & V & K\end{array}$

AGGGACCGGAAGACATCCCTGCTGCGACCAAGAAGCCCCCTGGCTTCAGG 1863

$\begin{array}{llllllllllllllllllll}585 & G & P & E & D & I & D & A & A & T & K & K & P & P & G & F & R\end{array}$

CCAGAAGCCGAGACCCACCCCCTGTATCTGGGGCACGATGTIGAGACCAA 1913

$\begin{array}{llllllllllllllllll}601 & P & \Xi & A & E & T & H & P & L & Y & L & G & H & D & V & E & T & N\end{array}$ CCTCTGAGgGCGAGgCCCGAGAaAgCCAATCACAGCCTCGgGCCAGCAgC 1963 $618 \quad I$

CTCCTCTCTGAATGGTTGGACCGTCACCTGTACAGAAGCTTGGCTGATAG 2013 AGGCCCTGCCCGCCCTGAAGTCCCTGTGTCCCACCTGCGCCCCCCAAAAG 2063 AGGGTTGGTTCTCTATCCACCAAGGAAAACATCTGGAACCGCAGTGACCT 211.3 TGTAGATTGCAGTAGGCAACTGAGAACACTCAGCTTCTCCAGACGGTGAG 2163 GTTITCCCATTTAACAAGCAGAGAAGCTGAGGGCGGTCACCCCAACGCTG 2213 GGAAGTAGAGGCAAGAAATTCAGGAGGTCAAGATCATCCGCAGCTACAG 2263 GCTGAGACCCACCCACC

Figure 1 Nucleotide and deduced amino acid sequences of mNIS. Nucleotides are numbered in the $5^{\prime}$ to $3^{\prime}$ direction beginning with the first base of the cloned sequence. The nucleotide sequence of mNIS reported in this paper has been submitted to the Genbank database. The accession number assigned to this sequence is AF235001.

cDNA were removed and an ideal Kozak sequence (Kozak 1997) was placed just upstream from the first initiation codon. Constructs carrying the NIS cDNA placed in either orientation downstream of the CMV promoter were obtained (pcDNA-mNISsense and pcDNA-mNISantisense constructs). COS-7 cells, transiently transfected with the recombinant pcDNA-mNISsense plasmid, accumulated, after 45 min incubation, a 15-fold higher concentration of ${ }^{125}$ I than cells transfected with the recombinant pcDNAmNISantisense or with the pcDNA3.1 vector (Fig. 3). Time-course accumulation revealed that equilibrium was reached after a $15 \mathrm{~min}$ incubation (not shown). In addition, this iodide accumulation by the mouse protein exhibits all the characteristics described for rNIS and hNIS. Iodide accumulation was inhibited in the presence of sodium perchlorate or thiocyanate and was also inhibited in cells previously incubated with the $\mathrm{Na}^{+}-\mathrm{K}^{+}$-ATPase inhibitor ouabain $(10 \mathrm{mM})$ or when the sodium concentration gradient across the membrane was collapsed with a mixture of the $\mathrm{Na}^{+}$ionophore monensin $(5 \mu \mathrm{M})$ and the protonophore trifluoromethoxyphenylhydrazone (FCCP) $(50 \mu \mathrm{M})$. Finally, iodide accumulation was not significant when sodium was replaced by choline, and decreased by $70 \%$ in experiments carried out at $4{ }^{\circ} \mathrm{C}$ (Fig. 3). All these data demonstrate that the identified protein indeed catalyses a sodium iodide symport activity.

To further characterise the kinetic properties of mNIS, Chinese hamster ovary $(\mathrm{CHO})$ cells were transfected with the pcDNA-mNISsense plasmid. A clone, named CHO-M, was isolated which stably expressed mNIS and concentrated iodide a 100-fold above the extracellular concentration (data not illustrated). Kinetic experiments as 
mNIS

rNIS

hNIS

mNIS

rNIS

hNIS

mNIS

rNIS

hNIS

MNIS

rNIS

hNIS

mNIS

rNIS

hNIS

mNIS

rNIS

hNIS

$\operatorname{mNIS}$

rNIS

hNIS

mNIS

rNIS

hNIS

mNIS

rNIS

hNIS

mNIS

rNIS

hNIS

mNIS

rNIS

hNIS

mNIS

rNIS

hNIS

mNIS

rNIS

hNIS
$\Theta$ MEGAEAGARATEGPWDYGVFATMLLVSTGIGLWVGLARGGQRSADDFFTG

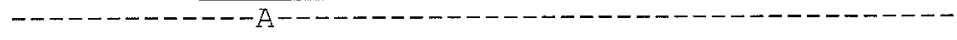
$--\mathrm{AV}-\mathrm{T}-\mathrm{E}-\mathrm{P}---\mathrm{A}-------\mathrm{I}-------------------\mathrm{E}-\cdots---$ GRQLAAVPVGLSIAASEMSAVQVLGVPAEAARYGLKELWMCVGQLLNSLL

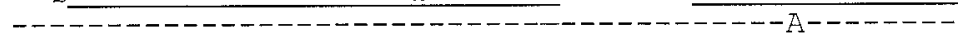
$--\mathrm{R}---\mathrm{L}------\mathrm{S}------------\mathrm{S}-\mathrm{Y}-----------\mathrm{L}------\mathrm{V}-$

TALLFLPIFYRLGLTSTYQYLELRESRAVRLCGTLQYLVATMLYTGIVIY

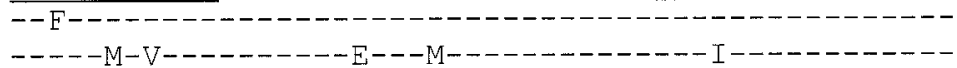

APAIILNQVTGLDIWASILSTGIICTIYTTVGGMKAVVWTDVEQVVVMLV

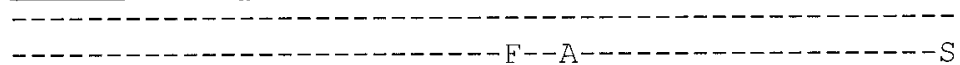
$\oplus \triangle$ GEWVILARGVMLMGGPWNVLSLAQNHSRINLMDFDPDPRSRYTEWTEVVG

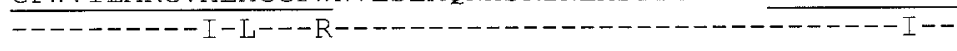
$----V-------V---R Q-T--------------N---------------$ GSLVWLSMYGVNQAQVQR RVACHTERKAKLALLVNQLGLELIVASAACCG

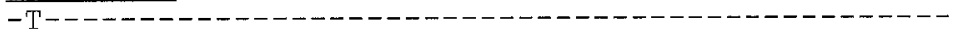
$-\mathrm{T}----------\cdots-------\mathrm{R}-\mathrm{KQ}-------\mathrm{I}--\mathrm{V}------\mathrm{S}------$

IVMEVYYKDCDPLITGRIAAPDQYMPLLVLDIEEDLPGVPGLFIACAYSG

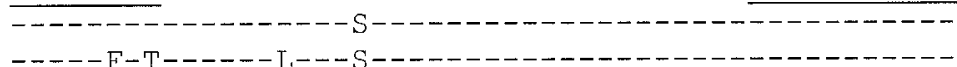

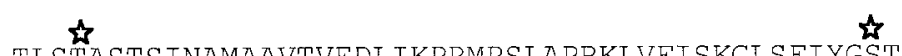
TLSTASTSINAMAAVTVEDLIKPRMPSLAPRKLVFISKGLSEIYGSTCLT

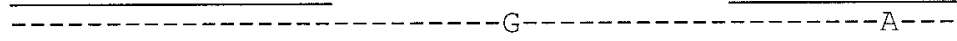

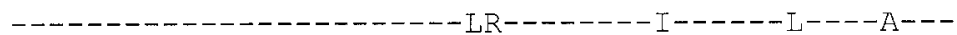
VAALSSLIGGGVLQGSETVMGVISGPLLGAFTLGMLLPACNTPGVLSGIT

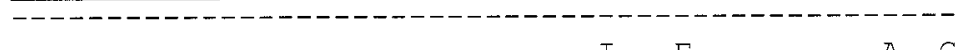
$---------------------------I---F----------A--G$

\section{$\triangle$}

AGLAVSLWVAVGATLYPPGEQTMGVLPTSAAGCTNASVLPS PPG A AGLAVSIWVAVGATLYPPGEQTMGVL RISAAGCIASV ----$----\mathrm{L}-----\mathrm{L}-------\mathrm{S}----\mathrm{R}---\mathrm{S}---\mathrm{R}-\mathrm{VAL}--\mathrm{NA}-\mathrm{GLLD}-\mathrm{ALLP}$

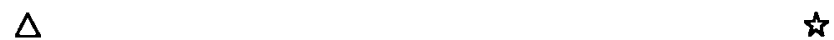

ANTSRGIPSSGMDSGRPAFADTEYAVSYLYYGALGTLTTMLCGALISYLT T-A-N------ T----I--A-D-SRA------AS---L--S-- I-- - - - - - - - $-------C--$

\section{$\mathbb{1}$}

GPTKRSSLGPGLLWWDLARQTASVAPKEDTTTLEDSLVKGPEDIPAATKK $--------------------------A---E--\cdots-------V---$ $-----\mathrm{T}-\mathrm{A}---------------$ EVAI-DDN------EL-TGN--

\section{II}

$\begin{array}{lcc}\text { PPGERPEAETHPLYLG } & \text { HD } & \text { VETNL } \\ --- \text { LK-G-------- } & -- & --- \\ --- \text { EL-TN-DRLFE--QKELEGAGSWTPCVG--GGRDQQ---- }\end{array}$

Figure 2 Alignment of the amino acid sequences of mNIS, rNIS and hNIS. Identical amino acids are marked with a hyphen (-). The 13 putative transmembrane domains are underlined and the charged amino acids within these domains are marked (encircled + or - ). Putative $\mathrm{N}$-linked glycosylation sites $(\Delta)$, potential phosphorylation sites for CAMP dependent protein kinase (black arrow) or PKC (open arrow) are also indicated. Stars indicate identified point mutations leading to iodide transport defects in humans. 


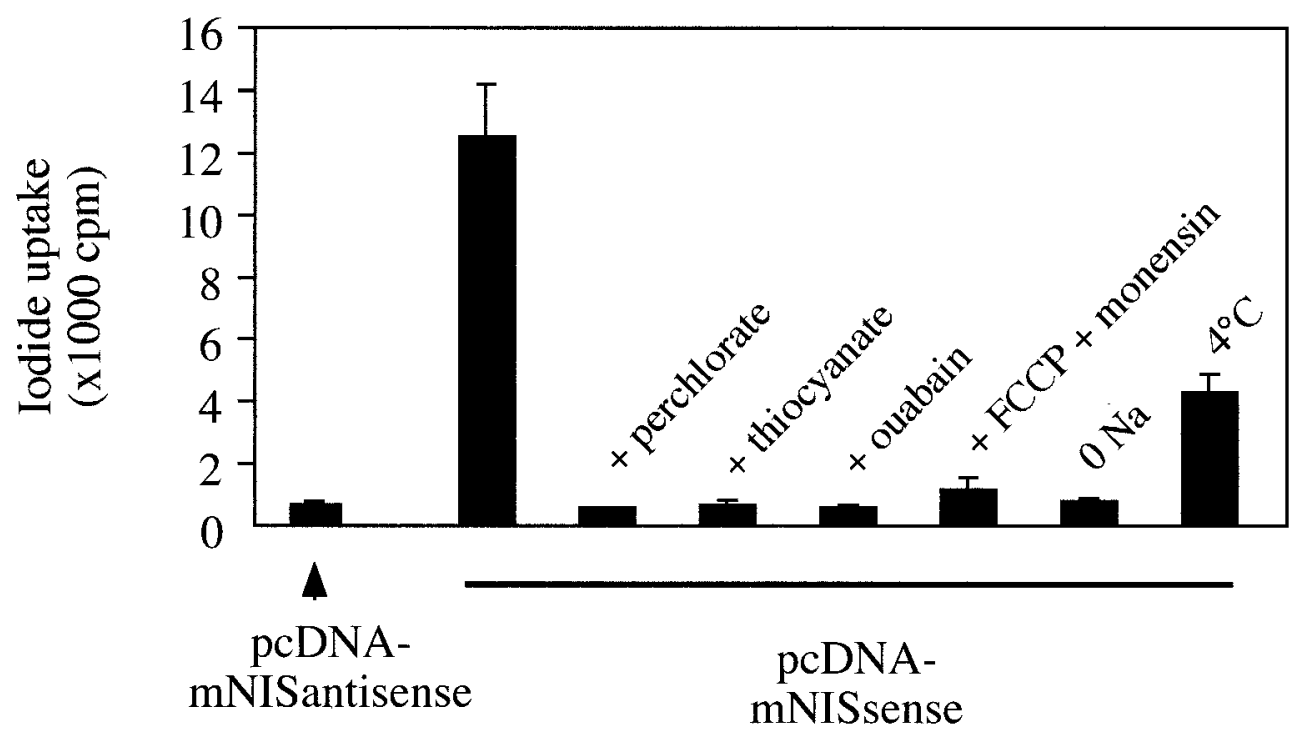

Figure 3 Functional expression of $\mathrm{mNIS}$ in COS-7 cells. COS-7 cells in 12-well plates were cultured in DMEM medium, containing $2 \mathrm{mM}$ glutamine and $10 \%$ fetal bovine serum (Life Technologies) at $37{ }^{\circ} \mathrm{C}$ in a $\mathrm{CO}_{2}$ incubator until the cells reached $\sim 70 \%$ confluence. At that stage, cells were transfected with the mNIS cDNA sequence cloned into the pcDNA3-1 vector either in the sense (pcDNA-mNISsense) or in the antisense orientation (pcDNA-mNISantisense) for a negative control. Transfected cells were further cultured for 2 days in the same culture medium. The cells were then washed twice with Hanks' balanced salt solution (HBSS) buffered with $10 \mathrm{mM}$ Hepes ( $\mathrm{pH} 7 \cdot 0$ ) (Life Technologies). lodide uptake assays were started by adding a buffered HBSS solution containing $50 \mu \mathrm{M} \mathrm{Na}{ }^{125} \mathrm{I}(50 \mathrm{Ci} / \mathrm{mol})$ and the cells were incubated at $37^{\circ} \mathrm{C}$ for $45 \mathrm{~min}$. Where indicated, the assay medium contained $1 \mathrm{mM}$ perchlorate, $150 \mu \mathrm{M}$ thiocyanate, $10 \mathrm{mM}$ ouabain or $50 \mu \mathrm{M}$ FCCP and $5 \mu \mathrm{M}$ monensin. Incubations were also carried out in an assay medium without sodium (substituted by an equimolar concentration of choline) and at low temperature $\left(4{ }^{\circ} \mathrm{C}\right.$ ). lodide uptake assays were carried out in triplicate. The assays were terminated by removing the radioactive solution and subjecting the cells to three quick washes with ice-cold buffered HBSS solution. Finally, cells were permeabilised with ethanol and released ${ }^{125}$ I was estimated by liquid scintillation counting.

a function of the iodide concentration $(6-300 \mu \mathrm{M})$ indicate an apparent iodide transport constant $\left(K_{\mathrm{m}}\right)$ of $36 \mu \mathrm{M}$, a value in close agreement with the constant reported for the FRTL-5 cell line from rat thyroid (Weiss et al. 1984), for rNIS expressed in Xenopus laevis oocytes (Dai et al. 1996, Eskandari et al. 1997) and in CHO cells (CHO-4J cell line that stably express rNIS (Kosugi et al. 1996)).

\section{Variation of $m$ NIS $m R N A$ level in the mammary gland in different physiological stages}

First attempts to study variation of the mNIS mRNA level in mammary gland in different physiological stages were carried out using Northern blot analysis. The recorded signals obtained with either ${ }^{32} \mathrm{P}$ - or biotin-labelled DNA or RNA probes were too low to detect significant variations in NIS mRNA amounts. These results indicated, however, that NIS RNA levels are very low and consequently that the use of a more sensitive approach was required. We then used a PCR-based technique, the mouse Rapid-Scan, that includes, among others, a set of PCR-tested first-strand cDNAs derived from mammary glands at different developmental stages (virgin, pregnant, lactating and involuting). Each set of cDNA contains low abundance and long mRNAs, and has been normalised using $\beta$-actin cDNA as an internal standard. Semiquantitative determination of relative mRNA level was achieved by using serially diluted cDNAs (4-log range). To minimise possible hybridisation artefacts, two sets of primers were selected to efficiently amplify two distinct mNIS cDNA fragments. Moreover, a 10-fold increase in detection sensitivity of the PCR products was achieved using GelStar stain instead of ethidium bromide.

Figure 4 shows that the highest level of NIS derived PCR products was obtained in the lactating stage. NIS mRNA levels of the mammary gland in developmental stages decreased in the order lactating $>>$ involuting $>$ virgin $>$ pregnant with the two different primer sets. In general, no additional bands were observed except two faint bands that appeared at a higher molecular mass with cDNAs of the lactating stage. Since the contribution of these bands to the overall signal is low $(<10 \%)$, they do not significantly interfere with our measurements. When compared with the signal in lactating mammary gland (set 

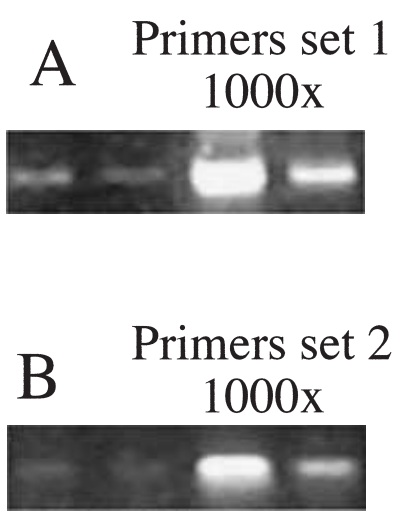
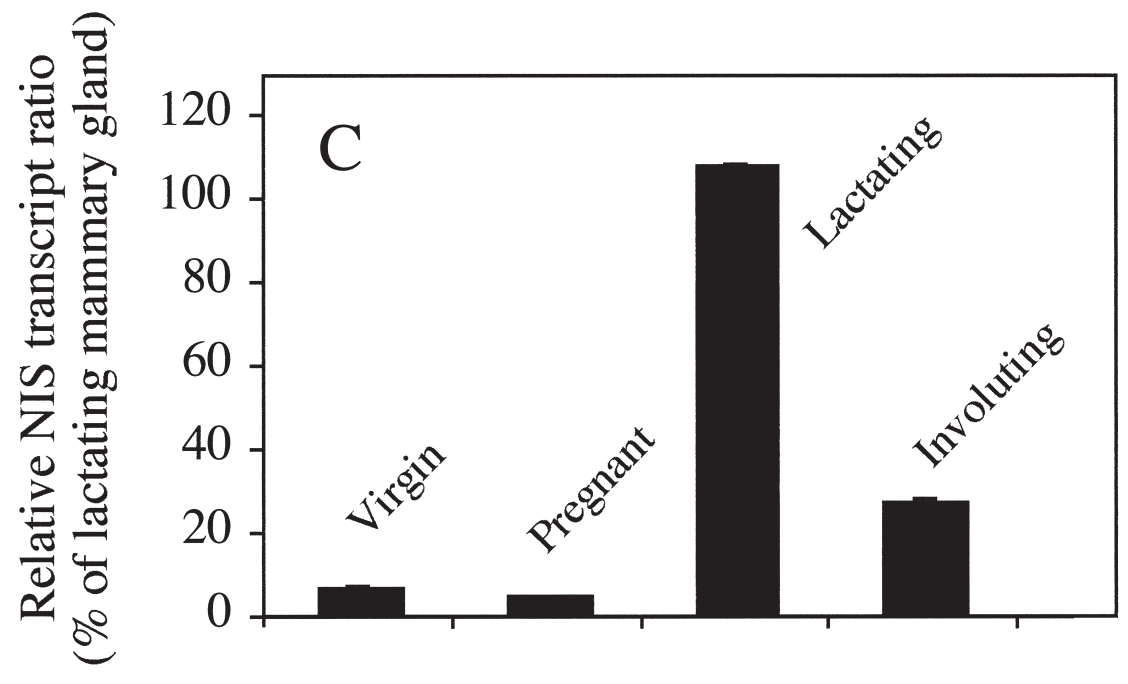

\section{Developmental stage of the mammary gland}

Figure 4 Dependence of the mNIS mRNA levels in the mouse mammary gland as a function of the tissue development. GelStar stained gels (A, B) illustrate the semi-quantitative analysis (Rapid-Scan method) of mNIS mRNA level: (A) $1 \mu$ l of each $1000 \times$ reaction (26 cycles) using primer set 1 ; (B) $10 \mu \mathrm{l}$ of each $1000 \times$ reaction (25 cycles) using primer set 2. (C) Quantitative estimates of mNIS mRNA levels. Densitometry of each band was analysed and signals from at least two GelStar stained gels were averaged. Results are presented as a percentage of the value measured for lactating mammary gland.

at $100 \%$ ), the signal intensity is approximately $6 \%$ in the virgin breast, $3 \%$ in the pregnant breast and $26 \%$ in the involuting breast.

Additional semi-quantitative RT-PCR experiments were carried out with total RNA extracted from mammary glands at different stages using a protocol similar to that used for analysis of the NIS mRNA levels in thyroid and stomach described below. This analysis (data not shown) confirms, at least qualitatively, that a higher expression occurs during the lactating stage. However, the differences between the two tissues were less marked.

Taken together, these data show that the mNIS mRNA level is significantly higher during the lactation period.

\section{Tissue expression of $m$ NIS $m R N A$ in mice}

Again analysis using Northern blots was initially attempted but the sensitivity was not high enough and semiquantitative RT-PCR was chosen. The Rapid-Scan system was used for the analysis in 16 tissues of the mouse. Each signal has been normalised to the signal measured in the lactating mammary gland (set at 100\%) (Fig. 5). For the sake of simplicity, the tissue signals were classified into four categories. A first group includes the lactating mammary gland and stomach where NIS is most highly expressed. The ratio of expression between these two tissues (1.7 higher for the stomach) is slightly lower than those obtained in semi-quantitative RT-PCR experiments reported above $(3 \cdot 3)$. This difference could result from variation in the quality of the RNA samples and/or could be due to the different sensitivity of the two techniques. In the second tissue category, mNIS mRNA amounts are $10-30 \%$ of the level detected in lactating mammary gland. This category is made up of the brain $(15 \%)$, small intestine (28\%), testis $(11 \%)$ and skin $(21 \%)$. The third group contains tissues expressing mNIS mRNAs at a rate not higher than $5 \%$ of that in the lactating mammary gland and includes the spleen, ovary and prostate gland. In the last group, we pooled tissues (kidney, thymus, muscle, adrenal gland, heart, lung, uterus and liver) where mNIS mRNA expression was hardly detectable, ambiguous or not detected.

As no thyroid first-strand cDNAs are included in the mouse Rapid-Scan system, the relative thyroid mNIS mRNA level was analysed by means of a semi-quantitative RT-PCR method. For comparison, the stomach and lactating mammary gland were used as positive and the liver as negative controls (see Fig. 5 and other previous experiments carried out on rat (Ajjan et al. 1998b, Kotani et al. 1998)). cDNA amplification was monitored by incorporating radioactively labelled nucleotides during the reaction. Only linear amplification was considered for the calculation of the initial amount of cDNA. A typical RT-PCR experiment, illustrated in Fig. 6 shows that the NIS mRNA levels decrease in the order thyroid $>$ stomach $>$ mammary gland $>>$ liver. The mean level $(n=3)$ in the thyroid and stomach was six and three times higher respectively than in the lactating mammary gland. Less than $1 \%$ of the lactating mammary gland level was 


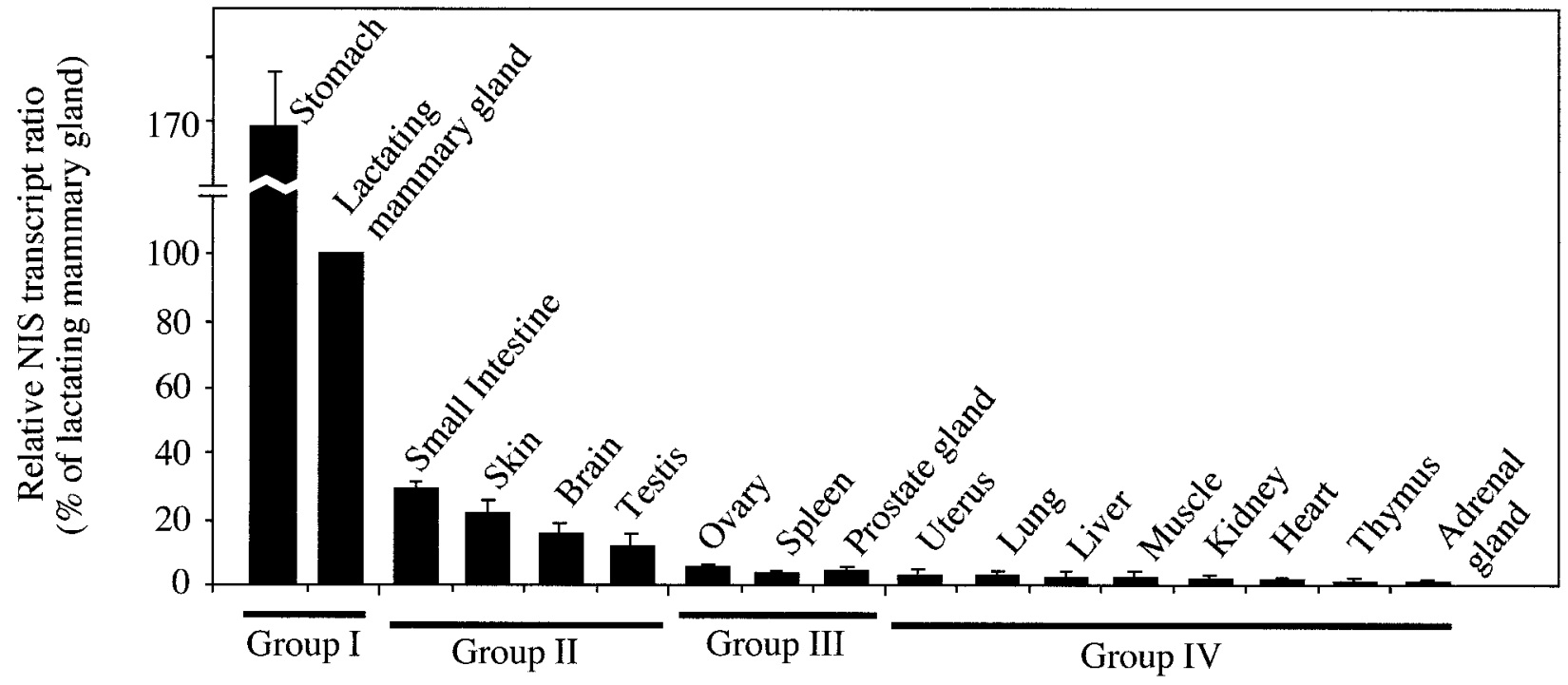

Figure 5 Tissue distribution of mNIS mRNA expression in mouse. Densitometry of GelStar-stained gels obtained from Rapid-Scan experiments. More than two gels in each of two independent experiments were used to calculate the mean. Data are presented as a percentage of the value obtained for lactating mammary gland.

found in liver. We confirmed by sequencing that the amplified thyroid and mammary gland cDNAs are 100\% identical.

\section{Discussion}

In the present study, we report the identification of the nucleotide and amino acid sequences of mNIS isolated from lactating mammary gland. As expected, sodium iodide symport activity is induced in cultured mammalian cells transfected with a recombinant vector carrying the mNIS gene. Analysis of the tissue distribution of mNIS RNAs revealed that mRNAs are expressed predominantly in the thyroid, stomach and lactating mammary gland. In addition, we report here for the first time that the level of mNIS mRNAs is specifically upregulated in the mammary gland during lactation.
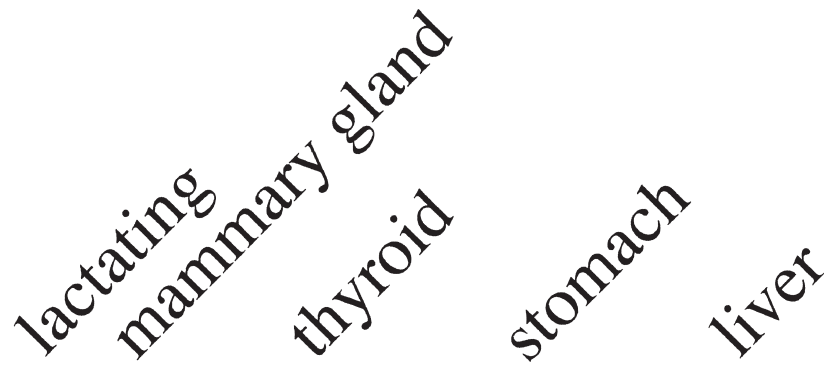 \\ NIS}
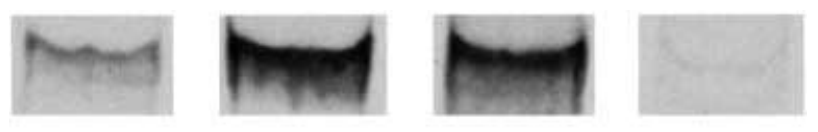

\section{$\beta$-actin}
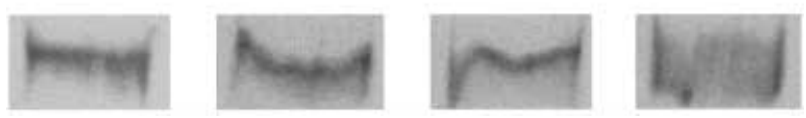

Figure 6 Comparative analysis of the levels of mNIS mRNAs in thyroid, stomach and lactating mammary gland using semi-quantitative RT-PCR. Autoradiograms of one typical RT-PCR experiment are shown. $\beta$-Actin specific primers were used for data normalisation (lower line). 
Table 1 Comparison of NIS mRNA expression in mouse, rat and human tissues. For each species, the value obtained in the thyroid tissue was taken as $100 \%(+++++)$

\begin{tabular}{|c|c|c|c|c|c|c|}
\hline & \multirow[b]{2}{*}{$\begin{array}{l}\text { Mouse } \\
\text { (Rapid-Scan } \\
\text { quantitative } \\
\text { RT-PCR) }\end{array}$} & \multicolumn{2}{|l|}{ Rat } & \multicolumn{3}{|l|}{ Human } \\
\hline & & $\begin{array}{l}\text { Quantitative } \\
\text { RT-PCR } \\
\text { (Ajjan et al. } \\
1998 b \text { ) }\end{array}$ & $\begin{array}{l}\text { Northern } \\
\text { RT-PCR } \\
\text { (Kotani et al. } \\
\text { 1998) }\end{array}$ & $\begin{array}{l}\text { Quantitative } \\
\text { RT-PCR } \\
\text { (Smanik et al. } \\
\text { 1997) }\end{array}$ & $\begin{array}{l}\text { Quantitative } \\
\text { RT-PCR } \\
\text { (Ajjan et al. } \\
\text { 1998a) }\end{array}$ & $\begin{array}{l}\text { RT-PCR } \\
\text { (Spitzweg et al. } \\
\text { 1998) }\end{array}$ \\
\hline \multicolumn{7}{|l|}{ Group I } \\
\hline Thyroid & +++++ & +++++ & ND & +++++ & $+++++^{f}$ & $\oplus^{\mathrm{g}}$ \\
\hline \multicolumn{7}{|l|}{ Group II } \\
\hline Small intestine & + & + & $+^{\mathrm{c}}$ & ND & ND & ND \\
\hline Skin & + & ND & $+^{\mathrm{d}}$ & ND & - & ND \\
\hline Brain & + & ND & $+^{\mathrm{e}}$ & ND & ND & ND \\
\hline Testis & + & ND & - & ND & ND & $\oplus$ \\
\hline \multicolumn{7}{|l|}{ Group IV } \\
\hline Uterus & - & ND & + & ND & ND & ND \\
\hline Lung & - & ND & - & ND & ND & - \\
\hline Liver & - & - & - & ND & ND & ND \\
\hline Muscle & - & ND & ND & - & ND & ND \\
\hline Kidney & - & - & - & - & ND & ND \\
\hline Heart & - & ND & - & - & ND & $\oplus$ \\
\hline Thymus & - & ND & - & ND & ND & $\oplus$ \\
\hline Adrenal gland & - & ND & - & ND & ND & $\oplus$ \\
\hline Other positives & ND & $\begin{array}{l}\text { Adipose } \\
\text { tissues }\end{array}$ & $\begin{array}{l}\text { Placenta } \\
\text { FRTL-5 }\end{array}$ & Colon & Salivary gland & $\begin{array}{l}\text { Salivary gland, } \\
\text { pituitary gland }\end{array}$ \\
\hline
\end{tabular}

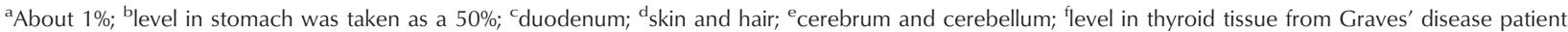
was taken as $100 \%$; ${ }^{g}$ data from non-quantitative RT-PCR experiments; ND = no data.

mNIS shares very high homology with the NIS already identified in other mammals. It has $95.5 \%$ identity to rNIS (98\% similarity) and $81 \%$ identity to hNIS $(89 \cdot 5 \%$ similarity). The length of the identified protein (618 amino acids) is identical to that of rNIS but is smaller than hNIS (643 amino acids). Several residues with a potential importance for the function and/or the stability of the protein (Pohlenz \& Refetoff 1999, Fujiwara et al. 2000), as well as glycosylation (Levy et al. 1998) and potential phosphorylation sites (Dai et al. 1996, Smanik et al. 1996) present in rNIS and hNIS are conserved in the mNIS sequence (Fig. 2). The iodide transport, induced in COS or $\mathrm{CHO}$ cells expressing mNIS, displays pharmacological and bioenergetic properties identical to other NISs. It is sodium dependent, greatly reduced at low temperature and inhibited by thiocyanate or perchlorate with an apparent iodide transport constant of $K_{\mathrm{m}}=36 \mu \mathrm{M}$.

Table 1 summarises the NIS expression in different tissues of the mouse (first column, this work) to that in rat and human (published data from other groups). To facilitate the comparison, values are normalised to the signal measured in the thyroid. As a function of mNIS mRNA measured levels, mouse tissues can be classified into four groups. Group I, with the highest levels, comprises, as expected, the thyroid (100\%), stomach $(50 \%)$ and lactating mammary gland (15\%). Group IV contains only tissues where no significant or hardly detectable amounts of mNIS mRNAs were found. Between these extremes, eight tissues were merged into two intermediate classes with a mRNA content either between 1.5 and $5 \%$ (group II: brain $(2 \cdot 2 \%)$, small intestine $(4 \cdot 2 \%)$, testis $(1 \cdot 6 \%)$ and skin $(3 \cdot 1 \%)$ ) or between 0.5 and $1 \%$ of the thyroid signal (group III: spleen, ovary, prostate and non-lactating mammary glands). This classification of the data for the mouse is thus similar to the tissue expression found for rat and human (Table 1). In particular, our data agree with the detection of significant levels of mRNAs previously reported for rat or human in the mammary gland, small intestine, skin, brain, testis, prostate and ovary (Table 1). However, part of the data obtained for human tissues (Ajjan et al. 1998a, Spitzweg et al. 1998) (Table 1, columns 5 and 6) are not consistent with our suggested 
classification. Ajjan et al. (1998a) and collaborators reported a much higher expression in the thyroid than in the stomach and also a non-significant signal from tissues classified in our groups II (skin) and III (ovary and spleen). These discrepancies could be explained by the fact that the data of Ajjan et al. (1998a) for the thyroid were obtained from a patient with Graves' disease, i.e. a pathological situation where NIS in the thyroid is overexpressed (Saito et al. 1997). Spitzweg et al. (1998) analysed the presence of the NIS mRNAs in different human tissues but they did not compare the relative mRNA levels. The physiological meaning of NIS expression in many of these tissues is not yet clear. It should be noted that our classification does not take into account factors such as cell tissue heterogeneity and/or the existence of functional units in given organs.

In the mouse mammary gland, our data show that the mNIS RNA level depends upon the developmental stage of the tissue, i.e. the level is higher in lactating than in nubile and mid-pregnant mice and during gland involution. This upregulation indicates that NIS transcription (and/or mRNA stability) in the mammary tissue is under hormonal control. Recently, upregulation of the NIS protein level in the rat mammary gland during lactation was reported (Cho et al. 2000, Tazebay et al. 2000). In addition, concomitant accumulation of iodide or technetium $\left({ }^{99 \mathrm{~m}} \mathrm{TcO}_{4}{ }^{-}\right)$in the rat mammary gland was detected by scintigraphic imaging during this particular stage of development (Cho et al. 2000, Tazebay et al. 2000). Our data further indicate that the NIS protein upregulation observed during lactation is at least partly due to an increase in its RNA level, but we cannot exclude an additional post-transcriptional regulation as has been reported in the thyroid (Kogai et al. 1997). The precise developmental stage at which NIS upregulation starts is still a matter of debate. An increase of the NIS protein level in the rat mammary gland during late pregnancy was observed by Tazebay et al. (2000) but not by Cho et al. (2000). The present cloning of mNIS will allow the determination of the precise developmental stage at which upregulation is initiated and how regulation proceeds during lactation and involution in mice. Simultaneous measurements of the variations of NIS mRNA and protein levels will be important to understand post-transcriptional and translational regulatory mechanisms in the mammary gland.

Recent work indicates that prolactin, oxytocin and oestrogens all contribute to the upregulation of the NIS protein in the mammary gland (Cho et al. 2000, Rillema et al. 2000, Tazebay et al. 2000). But the individual effects of hormones or their combined actions are complex and conflicting results were reported by the different groups. Substantial work is necessary to elucidate the hormonal regulation of the NIS in the mammary gland. The mNIS sequence should allow the use of knockout mice to assess the roles of hormone receptors and associated regulatory pathways, and thus potentially aid in exploring the possi- bility of diagnosis and radioiodide treatment of breast cancer patients.

\section{Acknowledgements}

This work was supported by grants from the Commissariat à l'Energie Atomique (CEA-LRC16V) and Electricité De France (EDF). We would like to thank Dr Sabine Lindenthal and Dr Patrick Chang for a critical reading of the manuscript and Dr M Rassoulzadegan and E Couchi from the animal centre of the University of Nice Sophia Antipolis for supplying mice.

\section{References}

Ajjan RA, Kamaruddin NA, Crisp M, Watson PF, Ludgate M \& Weetman AP 1998a Regulation and tissue distribution of the human sodium iodide symporter gene. Clinical Endocrinology 49 517-523.

Ajjan RA, Watson PF, Findlay C, Metcalfe RA, Crisp M, Ludgate M \& Weetman AP $1998 b$ The sodium iodide symporter gene and its regulation by cytokines found in autoimmunity. Journal of Endocrinology 158 351-358.

Bocchinfuso WP \& Korach KS 1997 Mammary gland development and tumorigenesis in estrogen receptor knockout mice. Journal of Mammary Gland Biology and Neoplasia 2 323-334.

Bole-Feysot C, Goffin V, Edery M, Binart N \& Kelly PA 1998 Prolactin (PRL) and its receptor: actions, signal transduction pathways and phenotypes observed in PRL receptor knockout mice. Endocrine Reviews 19 225-268.

Brown-Grant K 1961 Extrathyroidal iodide concentrating mechanisms. Physiological Reviews 41 189-213

Caturegli P, Hejazi M, Suzuki K, Dohan O, Carrasco N, Kohn LD \& Rose NR 2000 Hypothyroidism in transgenic mice expressing IFN-gamma in the thyroid. PNAS 97 1719-1724.

Chan S \& Kilby MD 2000 Thyroid hormone and central nervous system development. Journal of Endocrinology 165 1-8.

Cho JY, Leveille R, Kao R, Rousset B, Parlow AF, Burak WE, Mazzaferri EL \& Jhiang SM 2000 Hormonal regulation of radioiodide uptake activity and $\mathrm{Na}^{+} / \mathrm{I}^{-}$symporter expression in mammary glands. Journal of Clinical Endocrinology and Metabolism 85 2936-2943.

Dai G, Levy O \& Carrasco N 1996 Cloning and characterization of the thyroid iodide transporter. Nature $379458-460$.

De La Vieja A, Dohan O, Levy O \& Carrasco N 2000 Molecular analysis of the sodium/iodide symporter: impact on thyroid and extrathyroid pathophysiology. Physiological Reviews 80 1083-1105.

Eskandari S, Loo DDF, Dai G, Levy O, Wright EM \& Carrasco N 1997 Thyroid $\mathrm{Na}^{+} / \mathrm{I}^{-}$symporter. Mechanism, stoichiometry, and specificity. Journal of Biological Chemistry 272 27230-27238.

Fujiwara H, Tatsumi K, Tanaka S, Kimura M, Nose O \& Amino N 2000 A novel V59E missense mutation in the sodium iodide symporter gene in a family with iodide transport defect. Thyroid $\mathbf{1 0}$ 471-474.

Grosvenor CE $1963{ }^{131}$ I accumulation by lactating rat mammary gland. American Journal of Physiology 204 856-860.

Kilbane MT, Ajjan RA, Weetman AP, Dwyer R, McDermott EW, O’Higgins NJ \& Smyth PP 2000 Tissue iodine content and serum-mediated ${ }^{125} \mathrm{I}$ uptake-blocking activity in breast cancer. Journal of Clinical Endocrinology and Metabolism 85 1245-1250.

Kogai T, Endo T, Saito T, Miyazaki A, Kawaguchi A \& Onaya T 1997 Regulation by thyroid-stimulating hormone of sodium/iodide symporter gene expression and protein levels in FRTL-5 cells. Endocrinology 138 2227-2232. 
Kogai T, Schultz JJ, Johnson LS, Huang M \& Brent GA 2000 Retinoic acid induces sodium/iodide symporter gene expression and radioiodide uptake in the MCF-7 breast cancer cell line. PNAS $\mathbf{9 7}$ 8519-8524.

Kosugi S, Sasaki N, Hai N, Sugawa H, Aoki N, Shigemasa C, Mori T \& Yoshida A 1996 Establishment and characterization of a Chinese hamster ovary cell line, CHO-4J, stably expressing a number of $\mathrm{Na}^{+} / \mathrm{I}^{-}$symporters. Biochemical and Biophysical Research Communications 227 94-101.

Kotani T, Ogata Y, Yamamoto I, Aratake Y, Kawano JI, Suganuma T \& Ohtaki S 1998 Characterization of gastric $\mathrm{Na}^{+} / \mathrm{I}^{-}$symporter of the rat. Clinical Immunology and Immunopathology 89 271-278.

Kozak M 1997 Recognition of AUG and alternative initiator codons is augmented by $\mathrm{G}$ in position +4 but is not generally affected by the nucleotides in positions +5 and +6 . EMBO Journal 16 2482-2492.

Levy O, De la Vieja A, Ginter CS, Riedel C, Dai G \& Carrasco N $1998 \mathrm{~N}$-linked glycosylation of the thyroid $\mathrm{Na}^{+} / \mathrm{I}^{-}$symporter (NIS). Implications for its secondary structure model. Journal of Biological Chemistry 273 22657-22663.

Pohlenz J \& Refetoff S 1999 Mutations in the sodium/iodide symporter (NIS) gene as a cause for iodide transport defects and congenital hypothyroidism. Biochimie 81 469-476.

Rillema JA \& Yu TX 1996 Prolactin stimulation of iodide uptake into mouse mammary gland explants. American Journal of Physiology 271 E879-E882.

Rillema JA, Yu TX \& Jhiang SM 2000 Effect of prolactin on sodium iodide symporter expression in mouse mammary gland explants. American Journal of Physiology 279 E769-E772.

Saito T, Endo T, Kawaguchi A, Ikeda M, Nakazato M, Kogai T \& Onaya $\mathrm{T} 1997$ Increased expression of the $\mathrm{Na}^{+} / \mathrm{I}^{-}$symporter in cultured human thyroid cells exposed to thyrotropin and in Graves' thyroid tissue. Journal of Clinical Endocrinology and Metabolism 82 3331-3336.

Shyamala G 1999 Progesterone signaling and mammary gland morphogenesis. Journal of Mammary Gland Biology and Neoplasia 4 89-104.

Smanik PA, Liu Q, Furminger TL, Ryu K, Xing S, Mazzaferri EL \& Jhiang SM 1996 Cloning of the human sodium iodide symporter. Biochemical and Biophysical Research Communications 226 339-345.
Smanik PA, Ryu KY, Theil KS, Mazzaferri EL \& Jhiang SM 1997 Expression, exon-intron organization, and chromosome mapping of the human sodium iodide symporter. Endocrinology 138 3555-3558.

Spitzweg C, Joba W, Eisenmenger W \& Heufelder AE 1998 Analysis of human sodium iodide symporter gene expression in extrathyroidal tissues and cloning of its complementary deoxyribonucleic acids from salivary gland, mammary gland, and gastric mucosa. Journal of Clinical Endocrinology and Metabolism $\mathbf{8 3}$ $1746-1751$

Spitzweg C, Heufelder AE \& Morris JC 2000 Thyroid iodine transport. Thyroid 10 321-330.

Tazebay UH, Wapnir IL, Levy O, Dohan O, Zuckier LS, Hua Zhao Q, Fu Deng H, Amenta PS, Fineberg S, Pestell RG \& Carrasco N 2000 The mammary gland iodide transporter is expressed during lactation and in breast cancer. Nature Medicine 6 871-878.

Thorpe SM \& Briand P 1984 The ability to concentrate iodide as a marker of hormone dependence in GR mouse mammary tumors. International Journal of Cancer 34 127-131.

Tucker HA 1994 Lactation and its hormonal control. In The Physiology of Reproduction, pp 1065-1098. Eds E Knobil \& JD Neill. New York: Raven Press.

Vayre L, Sabourin JC, Caillou B, Ducreux M, Schlumberger M \& Bidart JM 1999 Immunohistochemical analysis of $\mathrm{Na}^{+} / \mathrm{I}^{-}$ symporter distribution in human extra-thyroidal tissues. European Journal of Endocrinology 141 382-386.

Weiss SJ, Philp NJ \& Grollman EF 1984 Iodide transport in a continuous line of cultured cells from rat thyroid. Endocrinology 114 1090-1098.

Welcsh PL \& Mankoff DA 2000 Taking up iodide in breast tissue. Nature 406 688-689.

Williams GR, Robson H \& Shalet SM 1998 Thyroid hormone actions on cartilage and bone: interactions with other hormones at the epiphyseal plate and effects on linear growth. Journal of Endocrinology 157 391-403.

Received 15 December 2000

Accepted 28 March 2001 